\title{
Porous Hydroxyapatite-Magnetite composites as carriers for guided bone regeneration
}

\author{
Sprio $S^{1}$, Panseri $S^{1}$, Adamiano $A^{1}$, Sandri $M^{1}$, Uhlarz $M^{2}$, Herrmannsdorfer $T^{2}$, Landi $E^{1}$, Pineiro-Remondo $\mathrm{Y}^{3}$, and Tampieri $A^{1 *}$ \\ ${ }^{1}$ ISTEC-CNR, Institute of Science and Technology for Ceramics, 48018 Faenza, Ravenna, Italy \\ ${ }^{2}$ Helmholtz-Zentrum Dresden - Rossendorf, D01328 Dresden, Germany \\ ${ }^{3}$ University of Santiago de Compostela, Spain
}

\begin{abstract}
Regeneration of critical size bone defects is still a major concern in orthopedics and requires the use of porous scaffolds with osteogenic and osteoconductive ability, able to boost cell activity towards the regenerative cascade. Even though magnetic-based targeted therapies for bone regeneration are very promising, they are affected by the low penetrating capacity of externally applied magnetic fields to reach the therapeutic site inside the human body. A strategy to overcome this pitfall is to implant magnetic scaffolds sensitive to magnetic stimulation or capable to be remotely activated by a calibrated magnetic field inside the patient body. In this work, we report on highly porous and magnetic scaffolds obtained by foaming process, consisting in hydroxyapatite matrices added with increasing amounts of magnetite nanoparticles. Extensive characterization of compositional, morphological, mechanical and magnetic properties was carried out, as well as a number of biological assays to extensively evaluate biological performances. The sintering temperature affected the magnetic properties of the materials by determining the phase transformation of magnetite into weakly magnetic or diamagnetic iron oxide phases such as hematite. However, this phenomenon was relevant only for scaffolds with a $50 \mathrm{wt} \%$ of magnetite, while below this value the hydroxyapatite matrix protected the magnetic phase from this transformation, thus ensuring the retention of valuable magnetic characteristics. The porous scaffolds exhibited good mechanical strength and magnetic properties enabling uses in hyperthermia-based therapies, displaying also high biocompatibility and cell conductivity into the inner part of the scaffold thanks to high open and interconnected submicro-ultramacro porosity.
\end{abstract}

\section{Introduction}

Bone is a living tissue that continuously rebuilds its structure in response to biomechanical stimulation. However, in spite of its ability of spontaneous regeneration that allows for healing of bone lesions of non-critical size, in case of large defects and osseous congenital deformities, a bone graft or bone substitute is needed to assist healing and regeneration of well-organized bone [1-5]. In this respect, the use of bioactive porous scaffolds associated with tissue engineering strategies has attracted many scientists and surgeons in the last two decades, in the perspective of treating patients by minimally invasive and less painful surgery. Scaffolds for regeneration of hard tissues must exchange suitable chemical, physical and topological signals with the surrounding extra-cellular matrix (ECM) in order to activate and promote the cascade of events at the cell level triggering the formation and 3-D organization of new bone tissue. The interaction between ECM and the implants surface is mediated by proteins adsorbed from the biological fluid that in turn transcribe the surface characteristics in information for cells [6]. In this respect, the design of biodevices acting as space and architecture holders for cell attachment and conduction plays a key role and many efforts were spent to develop macro-porous $\mathrm{CaP}$-based ceramic devices with suitable osteoconductive properties [7-10]. However, in spite of the improved performances offered by macroporous bone scaffolds, the repair/regeneration of large bone defects is still a concern, due to several factors including the insufficient cell conductivity in the scaffold core and the subsequent formation of necrotic zones. So far, many of the current tissue-engineering scaffold-based strategies have suffered from limited cell-depth viability when cultured in vitro, with viable cells colonizing the outer 250-500 micron from the fluidscaffold interface [11-14]. This is primarily believed to be due to the lack of angiogenesis extended to the inner parts of the scaffolds that, in association with an efficient nutrient delivery into and waste removal from the inner regions of the scaffold construct, could ensure a proper cell metabolism and the development of new bone with organized texture.

Biomaterials can be designed in a biomimetic perspective (i.e., with chemistry, morphology and porosity mimicking bone tissue), to elicit specific cellular responses thus directing new tissue formation. Hence, the cell-biomaterial interactions can be tuned and controlled by manipulating the parameters influencing the link between scaffolds and ECM proteins. In this respect hydroxyapatite (HA) based scaffolds are of significant interest since hydroxyapatite is the major inorganic component of natural bone [15]. To meet the need of rapid vascularization and improve the biomolecular recognition of materials by cells, advanced tissue engineering strategies should be established, such as the delivery of growth factors in situ [16]. The latter can be achieved by physical entrapment of the growth factors into the scaffold structure, its adsorption on the scaffold surface or through the formation of ionic complexes between the growth factor and the scaffold material [17]. The continuous spatially-controlled delivery of cells and/or specific growth factors such as Vascular Endothelial Growth Factor (VEGF) may provide a more rapid cell scaffold colonization so to make possible the control of both timing and quality of the new tissue formation by tailoring the growth factors delivery [18]. In order to reduce the invasiveness of surgical procedures, decrease hospitalization and the ever increasing healthcare costs, recent trends in biomaterials development concern the creation of intelligent devices

Correspondence to: Anna Tampieri, ISTEC-CNR, Institute of Science and Technology for Ceramics, 48018 Faenza, Ravenna, Italy

Received: February 02, 2017; Accepted: February 12, 2017; Published: February 20,2017 
able to be switched on in response to external signals, so to give a controlled and prolonged local assistance to tissue regeneration, also reducing unsuitable side effects [19]. Among the possible approaches, the use of magnetic fields in assisted tissue regeneration is of increasing interest and promises to open new perspectives for the development of regenerative and healing therapies, including the very wide field of oncology where non-invasive therapies based on hyperthermia are rapidly gaining ground.

There are several limitations to the clinical application of a magnetic field for targeted therapy of a magnetized drug or for cell delivery, due to the strong reduction of the intensity of externally applied magnetic fields with the distance to the target. Therefore, the triggering of drug release and administration in the target site by application of graded magnetic fields results hard to establish and control [20, 21]. These limitations can be circumvented by the introduction of superparamagnetic media that can be remotely activated by magnetic fields. By this approach, the magnetic moment of these media affords the potential for their continuous control and reloading with several tissue growth factors [22, 23]. The use of magnetic nanoparticles for biomedical applications is continuously increasing and recent studies also reported their use in tissue engineering [24-26].

In this respect, the present work establishes an innovative strategy to control the delivery of growth factors in vivo by mediation of external magnetic fields. Macro-porous bioactive ceramic composites were developed, by preparing hydroxyapatite matrices added with magnetite nanoparticles by foaming methods, with the purpose of generating an implantable workstation providing long-term maintenance to the implanted tissue engineered constructs and also offering the unique possibility to adjust the scaffold activity to the personal needs of the patient, overcoming the present difficulties of magnetic guiding [27]. The phase composition, morphology, mechanical strength and magnetic properties of the obtained scaffolds were studied; moreover biological characterization was carried out and assess adhesion, proliferation and morphology of osteoblasts in contact with the HA/ magnetite scaffolds.

\section{Materials and methods}

\section{Production of porous bodies}

The starting powders employed for the synthesis of the composite scaffolds were commercial hydroxyapatite (HA) and magnetite (Sigma Aldrich, Milan, Italy). The HA powder was preliminarily heat-treated at $1000^{\circ} \mathrm{C}$ for 5 hours in a conventional muffle furnace, then wet mixed with magnetite nanoparticles $(<50 \mathrm{~nm})$ in polyethylene jars for 8 hours, using zirconia grinding media. The resulting product was freeze dried and sieved below $150 \mu \mathrm{m}$, to obtain homogeneous HA/magnetite mixtures with different magnetite content. Three different mixtures were prepared and coded as A: HA/magnetite 95/5 wt\%; B: HA/ magnetite $90 / 10 \mathrm{wt} \%$; C: HA/magnetite $=50 / 50 \mathrm{wt} \%$; pure $\mathrm{HA}$ powder was taken as a reference and coded as $\mathrm{D}$. As furnished magnetite and magnetite sintered at $950^{\circ} \mathrm{C}$, hereinafter coded as $\mathrm{E}$ and $\mathrm{F}$, respectively, were used as additional reference materials.

Aqueous slurries containing $60 \mathrm{wt} \%$ of powder were prepared using 1.5 wt\% of Dolapix CA (Zschimmer \& Schwarz, Lahnstein, Germany) as a dispersant. After 6 hours of ball-milling with zirconia grinding media, the foaming was induced by addition of $1.4 \mathrm{wt} \%$ of Dermocin BS Conc (Fratelli Ricci, Italia) and further milling, upon completion of the foaming process, occurred after 8 hours. Then, the foamed suspensions were casted in adequate moulds and dried at room temperature for 48 hours.
The green porous bodies were sintered in a tubular furnace by heating at $100^{\circ} \mathrm{C} /$ hour up to $1200^{\circ} \mathrm{C}$ for 1 hour under a controlled atmosphere $\left(\mathrm{Ar} / \mathrm{H}_{2} 1.5 \mathrm{l} / \mathrm{min}\right.$ from 20 to $\left.400^{\circ} \mathrm{C}\right)$.

\section{Chemico-physical, morphological, mechanical and magnetic characterization}

Optical (Mic-D Digital Microscope, Olympus, Milano, Italy) and Scanning Electron Microscopy (SEM; Stereoscan 360, Leica, Cambridge, UK) equipped with RX microprobe (EDS: INCA 300, Oxford Instruments, UK) were used to assess the compositional homogeneity and to investigate morphological features at the macroscopic and microscopic scale. Pore size, pore interconnection and strut thickness were measured by image analysis assisted by a commercial software package (Image Pro-plus 4.5.1. Media Cybernetics, Silver Springs, MD).

The phase composition of the sintered composites was evaluated by means of full profile Rietveld analysis of the XRD spectra (TOPAS 4.2 software, Bruker AXS, Karlsruhe, Germany).

The apparent density of the sintered samples was geometrically determined by evaluating the mass/volume ratios of prismatic specimens. The porosity $\mathrm{P}$ was then calculated as $P=1-\rho / \rho_{t h}$, where $\rho$ and $\rho_{\text {th }}$ correspond to the measured and theoretical density values, respectively, of the $\mathrm{HA} /$ magnetite composites. The theoretical density was evaluated as $\rho_{t h}=\sum \rho_{i} x_{i}$, where $\rho_{\mathrm{i}}$ is the theoretical density of the $i^{\text {th }}$ phase present in the composite and $x_{i}$ its volume fraction as evaluated by XRD analysis;

The compressive strength of the porous composites was measured on cylindrical specimens of $10 \mathrm{~mm} \times 10 \mathrm{~mm}$ (height $\mathrm{x}$ diameter) using a Zwick/Roell Z050 instrument (Ulm, Germany) with a crosshead speed of $1 \mathrm{~mm} \cdot \mathrm{min}^{-1}$. The Young's modulus was approximated by calculating the slope of the linear, elastic portion of the stress-strain curves until the failure stress of the specimen.

Magnetization measurements were performed using a Superconducting Quantum Interference Device (SQUID) magnetometer (MPMS, Quantum Design, Inc., San Diego, USA). Small parts of magnetic scaffolds were prepared and fixed in a specially designed sample holder, which allowed removing background contributions from the total magnetic moment. For the acquisition of data, both the magnetic field and the temperature of the superconducting coil were kept constant while the sample was consistently moved through a pick-up coil system of the flux transformer connected to the SQUID. Sequences of such scans were performed while either the field or the temperature were stepwise swept in a wide range. Magnetization data were taken at fields, $-7 \mathrm{~T}<B<+7 \mathrm{~T}$, and at temperatures, $1.8 \mathrm{~K}<\mathrm{T}$ $<350 \mathrm{~K}$, using a liquid-He cooled variable-temperature insert installed in the commercial SQUID magnetometer set up. In order to scale the measured magnetic moments to the amount of substance, the weight of the sample was determined.

Measurements of magnetically induced hyperthermia were performed by placing each scaffolds in the center of a coil generating an alternating magnetic field of $0.03 \mathrm{~N} \mathrm{~A}^{-1} \mathrm{~m}^{-1}$ at a frequency $v=293$ $\mathrm{kHz}$ obtained by a homemade device.

\section{Biological characterization}

Cell Culture: MG63 Human Osteoblast-like cells were cultured in Dulbecco Modified Eagle's Medium (DMEM, PAA, Austria), containing penicillin/streptomycin $(100 / 100 \mathrm{U})$ supplemented with $10 \%$ foetal bovine serum (FBS) and kept at $37^{\circ} \mathrm{C}$ in an atmosphere of $5 \% \mathrm{CO}_{2}$. Cells were detached from culture flasks by trypsinization and 
centrifuged; cell number and viability were checked with trypan-blue dye exclusion test. All scaffolds were $10 \mathrm{~mm}$ diameter and $4 \mathrm{~mm}$ high, sterilized by $\gamma$-ray radiation $(25 \mathrm{kGy})$.

Biocompatibility tests: First level of cytotoxicity was analyzed by extract-indirect test. Extracts were obtained from materials under standardized conditions (ISO 10993-5:2009(E)). Briefly, samples were left in the extraction vehicle (i.e., cell culture medium) at $37^{\circ} \mathrm{C}$ for 24 $\mathrm{h}$. The pure extracts were added to cells, seeded in 24 multi-well plates $24 \mathrm{~h}$ before $\left(2 \times 10^{4} / \mathrm{ml}\right)$. Cells seeded without any extract were used as a blank group and cells seeded in presence of $0.05 \%$ phenol were considered as positive control. Cells were incubated for the following $24 \mathrm{~h}$ and $72 \mathrm{~h}$. The direct-contact test was performed on each group following the standardized conditions (ISO 10993-5:2009(E)). Cells were seeded in 6 multi-well plates $24 \mathrm{~h}$ before $\left(2 \times 10^{4} / \mathrm{ml}\right)$ and then the individual specimens were carefully placed on the cell layer in the centre of each of the replicate vessels covering approximately one tenth of the cell layer surface. Cells seeded without samples were considered as a blank group and cells seeded in the presence of $0.05 \%$ phenol were considered as positive control. Cells were incubated for the following $24 \mathrm{~h}$ and $72 \mathrm{~h}$. For both cytotoxicity tests, 5 samples for each material were used. At the end of extract-indirect test and direct-contact test, cell adhesion and morphology were evaluated by a phase-contrast microscope (Inverted Nikon Ti-E microscope, Tokyo, Japan) and cell viability was assessed using a Live/Dead viability kit and the MTT method.

Viability assay: samples were stained with the Live/Dead viability kit (Invitrogen, CA, USA). Briefly, the Live/Dead stain consists in Calcein acetoxymethyl (calcein AM) and Ethidium homodimer-1 (EthD-1) in 1X PBS solution. Samples were incubated with the stain for $15 \mathrm{~min}$ in the dark at $37^{\circ} \mathrm{C}$. Finally, the samples were rinsed three times in $1 \mathrm{X}$ PBS and analysed using an inverted Nikon Ti-E fluorescence microscope.

Proliferation test: for this assay MTT reagent (3-(4,5-dimethylthiazol-2-yl)-2,5-diphenyltetrazolium bromide) (Invitrogen) was added to cell culture $(0.5 \mathrm{mg} / \mathrm{ml})$ and incubated at $37^{\circ} \mathrm{C}$ for $3 \mathrm{~h}$. Afterwards, the unreacted dye was removed and dimethylsulfoxide was added to dissolve the intracellular insoluble purple formazan product into a coloured solution. The absorbance of the resulting solution was measured at $\lambda_{\max }$ of $570 \mathrm{~nm}$ on a spectrophotometric reader. The data collected was statistically analyzed by Two-way ANOVA test, followed by One-way ANOVA $(\mathrm{p}<0.05)$, by use of the GraphPad Prism software (version 5.0).

Morphological analysis: further investigation of cell adhesion and morphology was performed on cellseeded samples for each group, which were processed for SEM. A cell seeding on top of the scaffold was performed by dropping $100 \mu \mathrm{l}$ of cell suspension $\left(1 \times 10^{5}\right.$ cells $)$ onto the scaffold surface, and allowing cells attachment for 40 minutes $\left(37^{\circ} \mathrm{C}, 5 \% \mathrm{CO}_{2}\right)$, before addition of $1.5 \mathrm{~mL}$ medium in 24 multi-well plates. The medium was change every 2 days until the end of the experimental time (7 days). Osteoblasts grown on the materials were fixed in $2.5 \%$ glutaraldehyde, in $\mathrm{pH} 7.4$ cacodylate buffer $0.1 \mathrm{M}$ for $2 \mathrm{~h}$ and dehydrated in a graded series of ethanol. Samples were finely cut with a scalpel in order to examine also the internal surface. Dehydrated samples were sputter-coated with $10 \mathrm{~nm}$ of $\mathrm{Au} / \mathrm{Pd}$ using a Polaron Range sputter coater (DentonVacuum, USA) and mounted on a copper grid to be examined at Stereoscan 360 Scanning Electron Microscope (Cambridge Instruments).

\section{Results and discussion}

\section{Phase composition}

Figure 1 shows the XRD spectra of composites (A, B, C) and pure HA (sample D) after sintering. No other phases were detected beside hydroxyapatite (ICCD 09-0432) and magnetite (ICCD 19-0629) in sample $\mathrm{A}$ and $\mathrm{B}$, that displayed unchanged phase compositions with respect to the starting mixtures, even though the amount of magnetite detected in the sintered samples is lower than the nominal one, being in sample $\mathrm{A}=4 \%$ and in $\mathrm{B}=7 \%$. In sample $\mathrm{C}$, a substantial phase conversion of the magnetite introduced in the scaffold occurred, with about half of the original iron oxide transformed into hematite as an effect of the partial oxidation of iron during sintering. Apparently, the thermal decomposition of magnetite into other iron oxide phases occurred only at the highest nominal magnetite amount, whereas the calcium phosphate component retained its original habit independently from this parameter, so that no decomposition of HA occurred following sintering treatment. This finding suggests that hydroxyapatite acted as a protective matrix for the magnetic nanoparticles therein embedded, thus preventing their transformation into less functional iron oxide phases such as hematite.

\section{Microstructure and mechanical strength}

The sintered samples showed a total porosity ranging between 73 to $78 \%$, independently from the phase composition, hence, the presence of magnetite has not hampered the activity of the foaming agents in generating air bubbles, so that the whole process can be applied to a wide range of $\mathrm{HA} /$ magnetite compositions without significant variations of the process parameters. However, an effect related to the foaming of ceramic slurries with different formulations was detected when investigating the microstructures of the sintered porous bodies by SEM analysis. The microstructure of the sintered samples was characterized by large pores in the range $300-800 \mu \mathrm{m}$ uniformly distributed throughout the sample with extensive interconnections (average dimension $=100$ $150 \mu \mathrm{m}$ ) between the individual cells (see Figure. 2a-c). However, the composites showed a reduced pore interconnectivity, particularly in sample $C$, as reported by SEM analysis presented in Figure 2 . This effect could be due to the higher specific weight of magnetite particles $(\rho=$ $\left.5.2 \mathrm{~g} \mathrm{~cm}^{-3}\right)$ in respect to hydroxyapatite $\left(\rho=3.16 \mathrm{~g} \mathrm{~cm}^{-3}\right)$ that may have generated phase segregation and anisotropies in the ceramic slurry, that reflected into the phase distribution in the composite and the formation of interconnected bubbles during the foaming process [28].

The fracture surfaces are shown under higher magnification, revealing homogeneous microstructures where a residual intergranular porosity in samples containing magnetite is evident (Figure 2d-e), whereas pure HA showed good grain coalescence (Figure 2f). It is thus evident the effect of magnetite nanoparticles in hampering effective grain coalescence in HA/Mag composites. This effect was a major drawback penalizing the compressive strength in respect to pure HA scaffolds, in spite of their similar total porosity (Table 1). Anyway, the mechanical strength values found for sample $A$ is in the range of typical values exhibited by cancellous bone [29], thus being promising for practical application in bone tissue engineering. Remarkably, the compressive strength of the sample A was similar to that of pure HA scaffolds with much lower porosity (i.e., 50 vol\%), sintered at higher temperature (i.e., $1250^{\circ} \mathrm{C}$, that is the typical conditions used for $\mathrm{HA}$ ), and prepared with the replica technique [30]. This suggests that foaming process is an effective method to generate porous ceramics with enhanced structural homogeneity, that reflects into higher mechanical strength. 


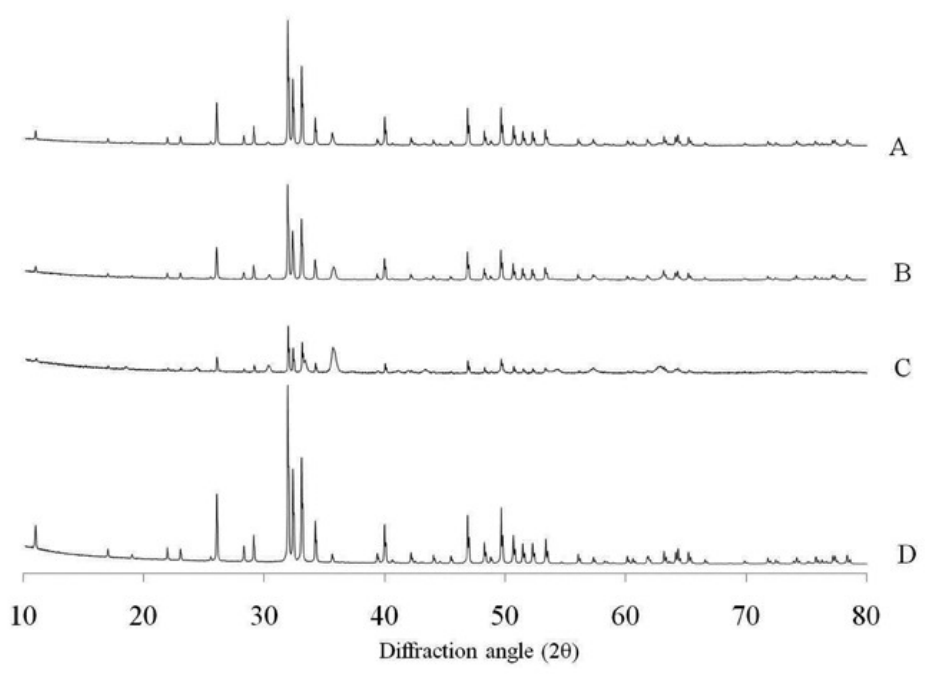

Figure 1. XRD spectra of HA and magnetic composites after sintering.
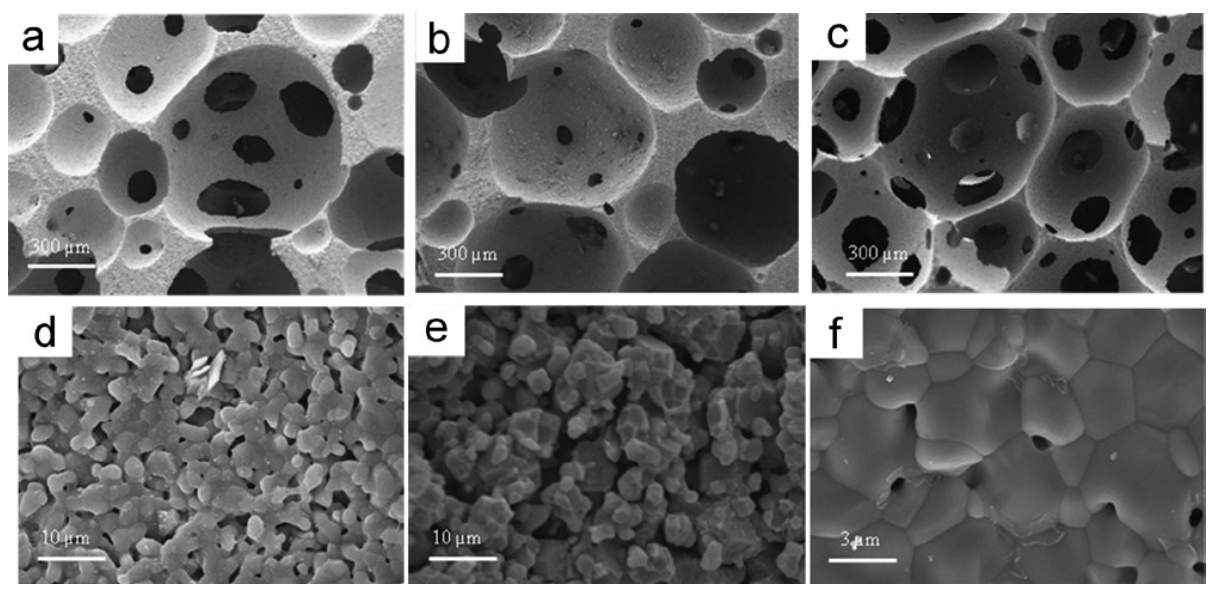

Figure 2. Microstructure of magnetic composites A (a-d), C (b-e), and D (c-f).

Table 1. Compressive strength of the porous foamed scaffolds prepared with slurries characterized by different magnetite loading.

\begin{tabular}{|c|c|c|c|}
\hline Sample & Porosity (\%) & $\begin{array}{c}\text { Compression } \\
\text { Strength (MPa) }\end{array}$ & E (GPa) \\
\hline A & $74 \pm 6$ & $3.71 \pm 1.25$ & $0.34 \pm 0.10$ \\
\hline B & $76 \pm 3$ & $0.79 \pm 0.31$ & $0.10 \pm 0.06$ \\
\hline C & $78 \pm 4$ & $0.32 \pm 0.17$ & $0.03 \pm 0.02$ \\
\hline D & $75 \pm 4$ & $4.05 \pm 1.40$ & $0.41 \pm 0.07$ \\
\hline
\end{tabular}

\section{Magnetic characterization}

The scaffolds added with magnetite still displayed a typical superparamagnetic behaviour after sintering, as shown by the hysteresis loop in Figure 3. A typical zero-field cooling cycle is shown for sample C in Figure 3b. The warming curve after zero-field cooling (ZFC) displays marks around $T=50 \mathrm{~K}$ and around $120 \mathrm{~K}$ which can be interpreted as traces of the Verwey transition, a complex crystallographic distortion of the $\mathrm{Fe}_{3} \mathrm{O}_{4}$ crystal structure. Consistently, for all the three composites (samples A-C), a blocking temperature of $T_{\text {block }}=120 \mathrm{~K}$ was derived from the respective $\mathrm{ZFC}$ curves, confirming that the diameters of magnetite particles are similarly distributed. However, the low slope of the curve at temperature below $T_{\text {block }}$ marks a wide blocking-temperatures region, pointing out the wide size-distributions of the magnetite nanoparticles incorporated in scaffolds C. As an example of the magnetic behaviour of the produced samples, a typical hysteresis loop collected on this latter sample is reported in Figure $3 \mathrm{~b}$. At body temperature $\left(37^{\circ} \mathrm{C}\right)$, the saturated magnetic moment per sample mass was proportional to the amount of magnetite inserted in the scaffold, and corresponded to 2.1, 5.5 and $21.0 \mathrm{emu} / \mathrm{g}$ for samples A, B and C respectively. The saturated moment increases almost linearly with the magnetite content, and a proportionality constant was calculated as the slope of the curve reported in Figure 3c, resulting in $0.43 \mathrm{emu} / \mathrm{g}$ per wt $\%$ of magnetite in the sample. In the considered range of magnetite concentrations, the coercive field evaluated from the hysteresis loop collected on the sintered scaffolds increased from 100 Oe for a magnetite content of $5 \%$ (sample A) to 300 Oe for a magnetite content of 50\% (sample C). This expansion of the magnetic remanence is probably due to an increase of the magnetic interactions between nanoparticles prompted by their higher concentration within the hydroxyapatite matrix.

Additional reference samples consisting in pure magnetite, not sintered and sintered at $950^{\circ} \mathrm{C}$ in $\mathrm{Ar} / \mathrm{H}_{2}$ atmosphere. Hereafter coded as samples $\mathrm{E}$ and $\mathrm{F}$ respectively, were characterized as well to have a 
a)

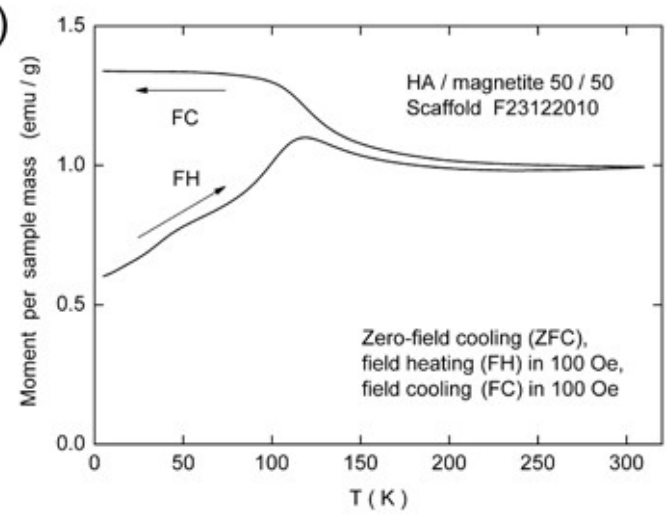

b)

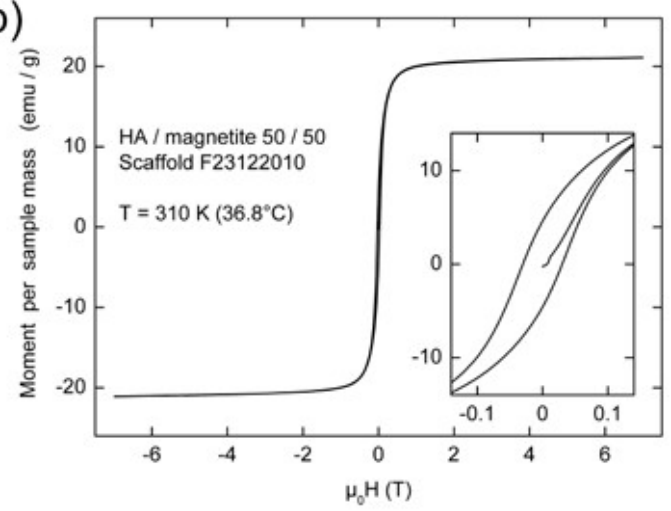

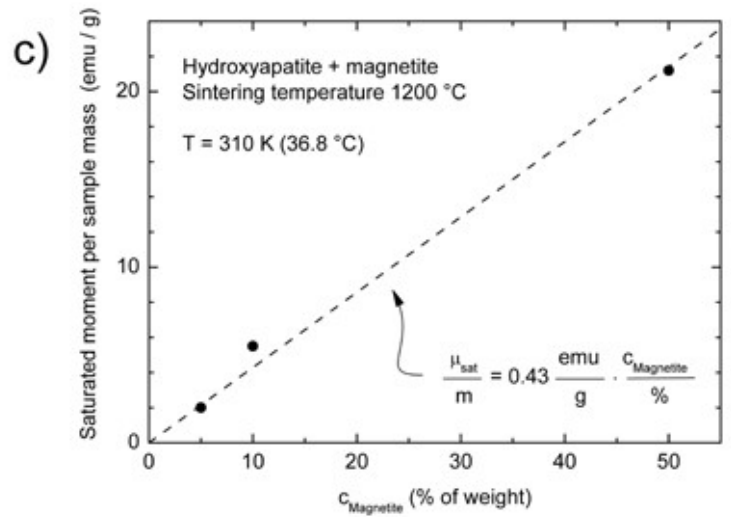

Figure 3. Zero-field cooling curve (a) and the hysteresis loop (b) of sample $\mathrm{C}$, with the curve obtained by plotting the recorded mass magnetization (emu/g) as a function of magnetite concentration ( $\left.w t^{\%} \%\right)$ of samples A, B and C (c).

direct comparison between the obtained composite scaffolds and a pure magnetic phase. The not-sintered and sintered samples showed mass-specific magnetization values of 69.9 and $79.0 \mathrm{emu} / \mathrm{g}$ at room temperature in an external field of $B=0.25 \mathrm{~T}$, which is consistent with the values expected for pure magnetite.

In order to collect additional evidences on the occurrence of a phase transformation induced by the temperature, we calculated the specific magnetizations of composites sintered at $1200^{\circ} \mathrm{C}$, in terms of magnetic moment per nominal mass content of magnetite and compared them to the sintered pure-magnetite sample. The resulting values were reported in Table 2.

The sintering of magnetite at $1200^{\circ} \mathrm{C}$ under $\mathrm{Ar} / \mathrm{H}_{2}$ can bring to the formation of wüstite or hematite, having mass-specific magnetization of 0.59 and $0.47 \mathrm{emu} / \mathrm{g}$ respectively. Considering that (i) the massspecific magnetization value of magnetite after sintering was of 79 $\mathrm{emu} / \mathrm{g}$ and (ii) that the sintered scaffold were all added with different amounts of magnetite, from the recorded mass magnetization values, we estimated that the $30 \%, 32 \%$ and $53 \%$ of magnetite for samples A, B and $\mathrm{C}$ respectively, were thermally decomposed into much less magnetic iron oxide phases, e.g. in hematite, as showed in the XRD profile collected on sample C. It is important to note that these values are reliable only assuming that the phase transformation of magnetite has not sorted any effect on the scaffold density, as severe changes in the weight on volume ratio will largely affect the measured mass magnetization values.

In conclusion, we found that the sintering process at $1200^{\circ} \mathrm{C}$ remarkably affected the magnetic properties of the sample, and that the
Table 2. Scaffold composition before sintering, sintering temperature and magnetic moment normalized on the effective magnetite content

\begin{tabular}{|c|c|c|c|}
\hline Sample code & $\begin{array}{c}\text { Composition HA } / \\
\text { Mgn (\%) }\end{array}$ & $\begin{array}{c}\text { Sintering } \\
\text { temperature }\left({ }^{\circ} \mathrm{C}\right)\end{array}$ & $\begin{array}{c}\text { Magnetic moment per } \\
\text { gram of magnetite } \\
(\mathrm{emu} / \mathrm{g})\end{array}$ \\
\hline $\mathrm{A}$ & $95 / 5$ & 1200 & 55.2 \\
\hline $\mathrm{B}$ & $90 / 10$ & 1200 & 53.1 \\
\hline $\mathrm{C}$ & $50 / 50$ & 1200 & 37.2 \\
\hline $\mathrm{D}$ & $100 / 0$ & 1200 & --- \\
\hline $\mathrm{E}$ & $0 / 100$ & --- & 69.9 \\
\hline $\mathrm{F}$ & $0 / 100$ & 950 & 79.0 \\
\hline
\end{tabular}

consequent mass magnetization of the scaffold decreased by lowering the hydroxyapatite/magnetite ratio. According to the XRD data previously reported, the magnetite incorporated in the scaffold was thermally decomposed in other iron phases whose specific mass magnetization is much lower, determining in this way a deviation from the expected magnetic behaviour (i.e., low mass magnetization value). This deviation from the expected results was more evident for sample $\mathrm{C}$ than for sample $\mathrm{A}$ and $\mathrm{B}$, with the two latter samples displaying a specific mass magnetization for gram of magnetite close to the sintered reference magnetite $(\mathrm{F})$, and the former displaying a much lower specific mass magnetization.

The reported data further confirm that hydroxyapatite sorted a protective effect on the magnetite nanoparticles, by preventing their phase-decomposition into antiferromagnetic (e.g. hematite) or less magnetic iron phases (wüstite), and hence preserved the magnetic properties of the original magnetic nanomaterial. 
The sintered scaffolds displayed hyperthermia properties when subjected to an alternating external magnetic field in agreement with their phase composition after thermal treatment at $1200^{\circ} \mathrm{C}$. As an example, the hyperthermia curves collected on scaffold A and $\mathrm{B}$ are shown in Figure $4 \mathrm{a}$ and $4 \mathrm{~b}$ respectively. The maximum temperature increases were recorded in the first minutes of magnetic field application and their value were proportional to the amounts of magnetite nominally incorporated in the samples, regardless of its transformation into maghemite/hematite or other iron oxides during sintering. More in detail, sample A reached a maximum increase of $7^{\circ} \mathrm{C}$ from $25^{\circ} \mathrm{C}$ (room temperature) to $32^{\circ} \mathrm{C}$ after 3 minutes of exposure to the magnetic field; after that no further temperature increase was recorded. Sample B displayed a similar behaviour, but in this case, the maximum temperature increase was of $17^{\circ} \mathrm{C}$ (from $24^{\circ} \mathrm{C}$ to $41^{\circ} \mathrm{C}$ ) after 5 minutes of exposure to the applied magnetic field. These results were in perfect agreement with the phase composition detected by $\mathrm{XRD}$, as with the magnetic properties of the sintered samples.

\section{In vitro cell testing}

The testing of biocompatibility issues in the development of new and innovative materials is a mandatory exploratory focus for the potential employment in medical practise of novel biomaterials. Biological evaluation of cytotoxicity of biomaterials were tested in vitro according to ISO 10993-5:2009. Extractindirect test and direct-contact test were performed following the standardized conditions described in the aforementioned protocol.

The first level of biomaterial cytotoxicity was tested by the extractindirect test. Extraction provides a measure of the hazard potential of the material using conditions that shorten the time for leaching of the substances into the medium. The pure extracts of each group, obtained by leaving the samples in the cell culture medium at $37^{\circ} \mathrm{C}$ for $24 \mathrm{~h}$, were added to human osteoblast-like cells seeded a day before. After $24 \mathrm{~h}$ and $72 \mathrm{~h}$ cell, cell adhesion and morphology were evaluated by a phasecontrast microscope. As expected, the positive control group showed a great amount of detached cells. In all the other groups no differences were seen compared to the blank group. The cells were spread and they showed a very good morphology at both experimental times (Figure 5AB). Cell viability was assessed also by the Live/Dead assay, results obtained showed that almost all seeded cells were alive and very few cells were dead without any difference between the magnetic samples, the HA group and the blank group (data not shown). According to the ISO 10993-5:2009, this first qualitative evaluation proved that the innovative investigated biomaterials had none cytotoxicity effect on cell culture.

This result of material biocompatibility was also measured by the quantification of cell proliferation in the MTT colorimetric assay. The results showed no significant differences in cell viability between each group after $24 \mathrm{~h}$ or $72 \mathrm{~h}(\mathrm{p}<0.05)$, except for the positive control that provided a reproducible cytotoxic response $(1.381 \pm 0.074(24 \mathrm{~h}) ; 1.913$ $\pm 0.041(72 \mathrm{~h})$; data not included in the graph) (Figure 6A).

After these encouraging results, a direct-contact test was performed as the second level of biocompatibility. Following the standardized conditions, samples of each group were carefully placed on the cell layer surface.

After $24 \mathrm{~h}$ and $72 \mathrm{~h}$, human osteoblast-like cells showed a good adhesion and morphology, moreover no reactivity zone was detected under or around each specimen (Figure 5C). Live/Dead assay proved that biomaterials were biocompatible, showing a very high ratio of live cells compared to the very few dead cells (Figure 5D). Also in this case, qualitative results were confirmed by quantitative analysis with the MTT test. Cell viability did not change between each group supporting the idea that magnetic samples were comparable to the non magnetic biomaterial and to blank group $(\mathrm{p}<0.05)$ (Figure 6B). Also in this case the positive control, not included in the graph, showed a reproducible toxicity $(1.874 \pm 0.036(24 \mathrm{~h}) ; 1.652 \pm 0.075(72 \mathrm{~h}))$.

SEM analysis was performed in order to verify cell morphology and colonization of the scaffolds. Cells were seeded directly onto the scaffold surface and after 7 days the analysis showed how the cells were attached and spread to the surface of all magnetic scaffolds without any observable difference compared to the HA scaffold (Figure 7A-B). The cells covered almost all the scaffold upper surface and they colonized also the inner scaffold surface (Figure 7C). The interconnected pores of the proposed novel biomaterials enhance the cell migration through the whole scaffold. According to this in vitro study, the results obtained are primarily indicators of good in vitro biocompatibility of the novel magnetic scaffolds, in fact no differences in morphology and proliferation were seen with both extract-indirect and direct-contact tests.

SEM analysis shows how the cells not only covered the upper surface, but they also grew into the scaffolds through their interconnected
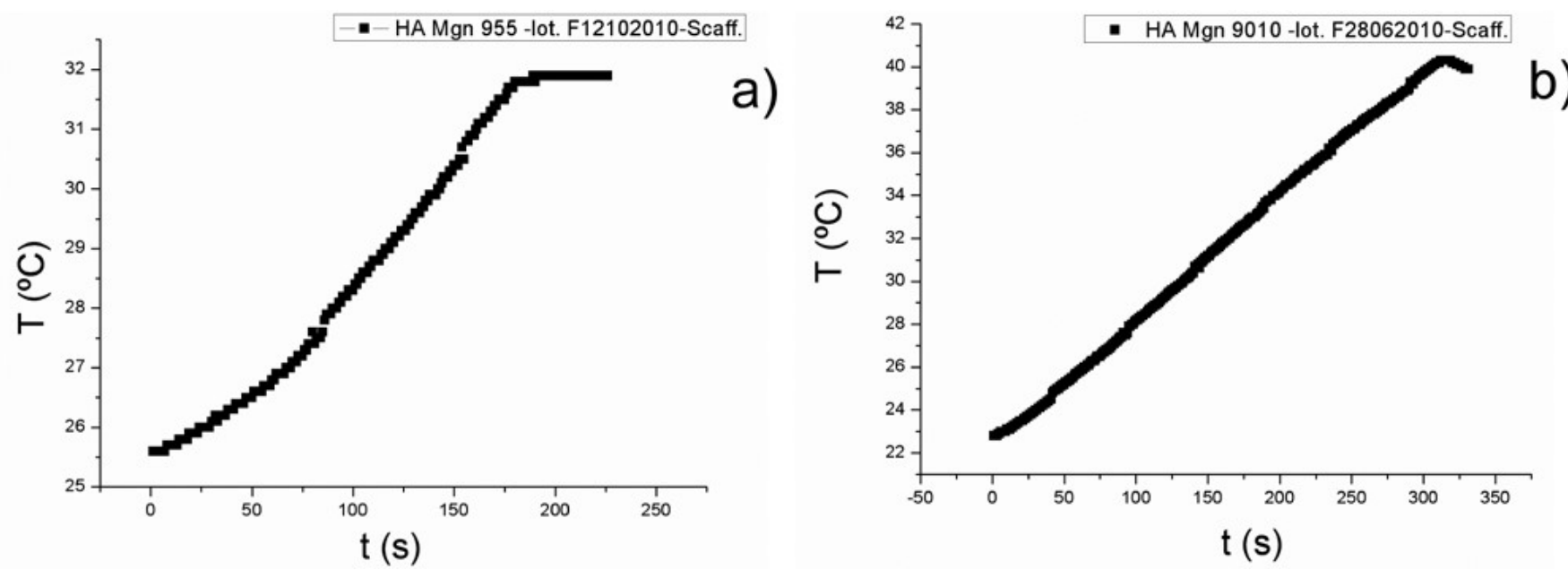

Figure 4. Hyperthermia curves obtained by plotting the temperatures of scaffold A (on the left) and scaffold B (on the right) as a function of time in presence of an external magnetic field with an intensity of $B=0.03 \mathrm{~T} \mathrm{~A}^{-1} \mathrm{~m}^{-1}$ and a frequency of $f=293 \mathrm{kHz}$. 


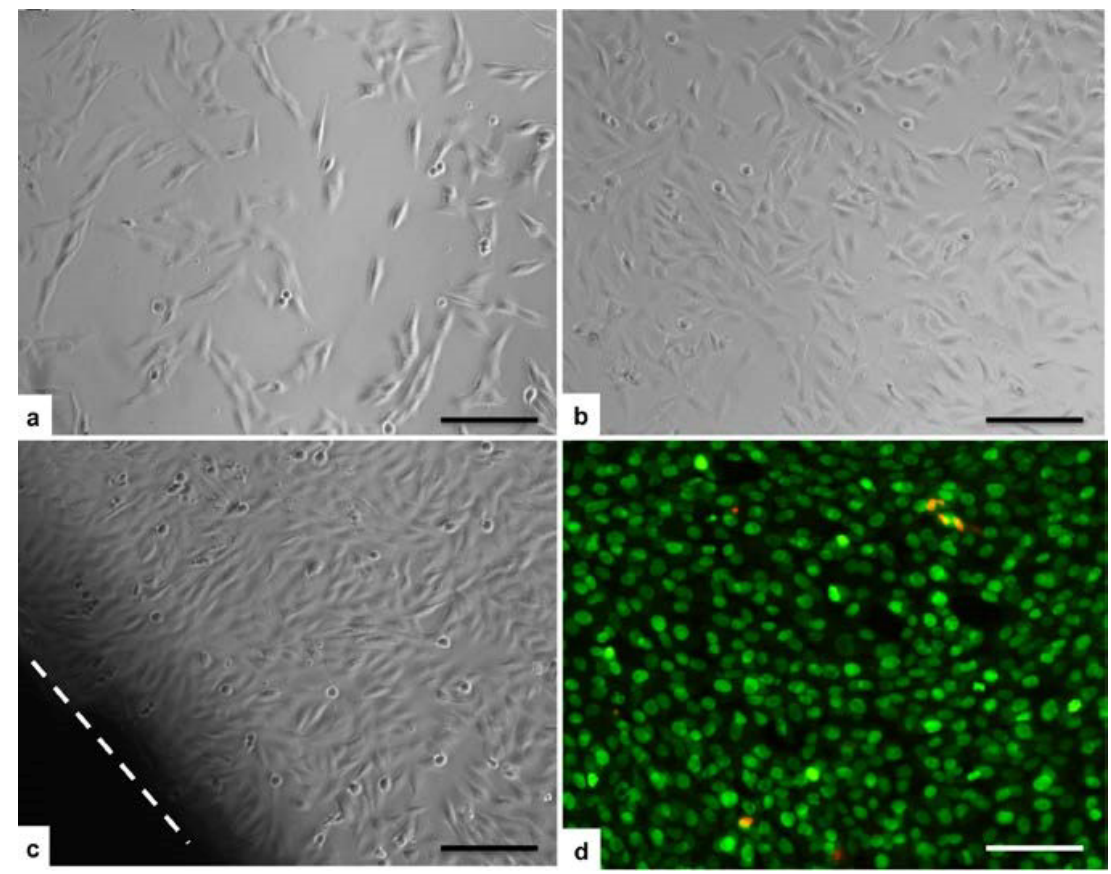

Figure 5. Biocompatibility analysis: Extract test. Investigation with phase-contrast microscope showed good cell adhesion and morphology in all the magnetic material groups comparable to the blank group. Sample C at $24 \mathrm{~h}$ (A), sample B at $72 \mathrm{~h}$ (B). Direct-contact test: the cell layer was not negatively affected by the scaffold in any group. No zone around every sample was seen, as shown for the sample B at $72 \mathrm{~h}(\mathrm{C}$, the dotted line indicate the scaffold outline). Cell viability by Live/Dead assay showed that almost all seeded cells were alive and very few cells were dead without any difference between the magnetic samples, the HA group and the blank group (D, Sample B at $72 \mathrm{~h}$; green=live cells; red=dead cells). (Scale bars $200 \mu \mathrm{m}$ ).

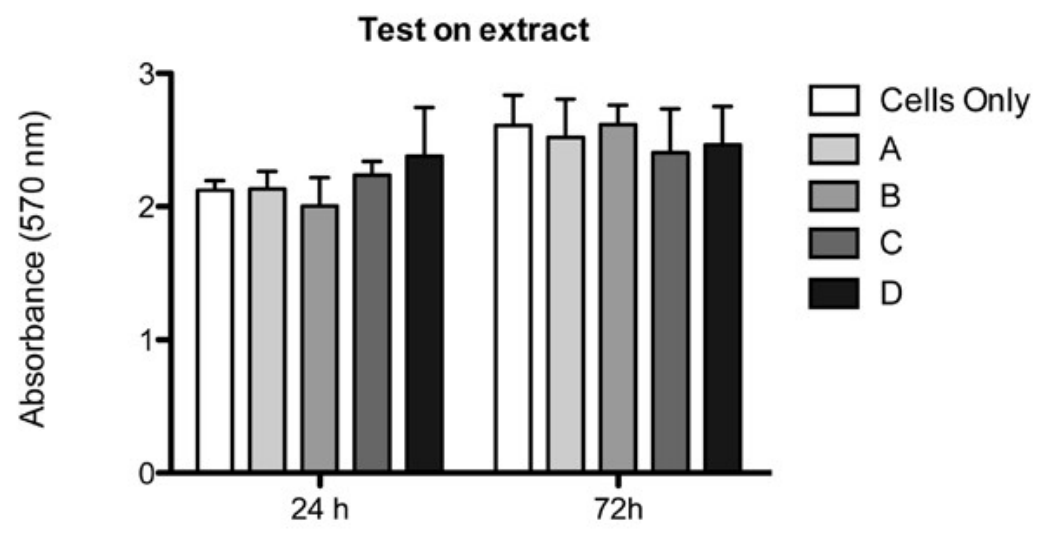

Test by direct-contact

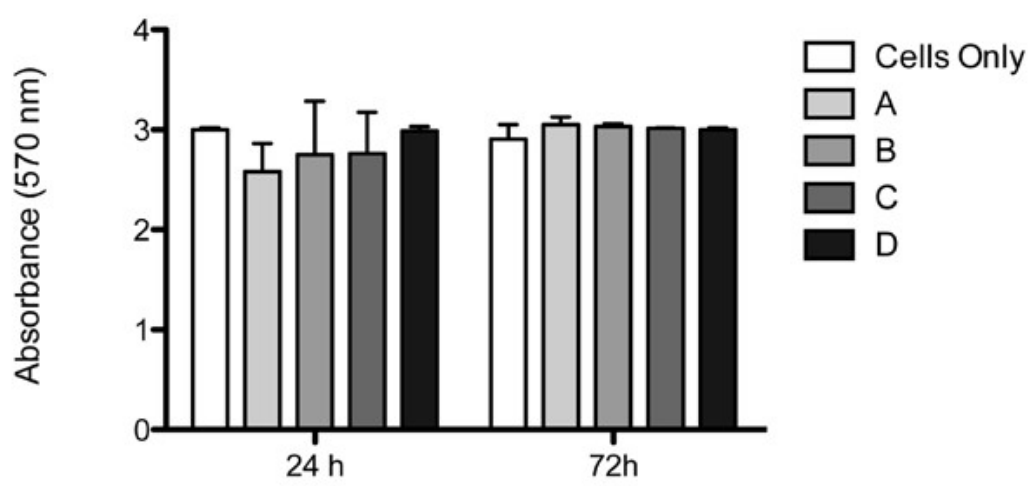

Figure 6. Proliferation assay:MTT test showed that in both extract test (A) and direct-contact test (B) no significant differences were seen between groups. ( $\mathrm{p}<0.05$; Mean \pm SD). 

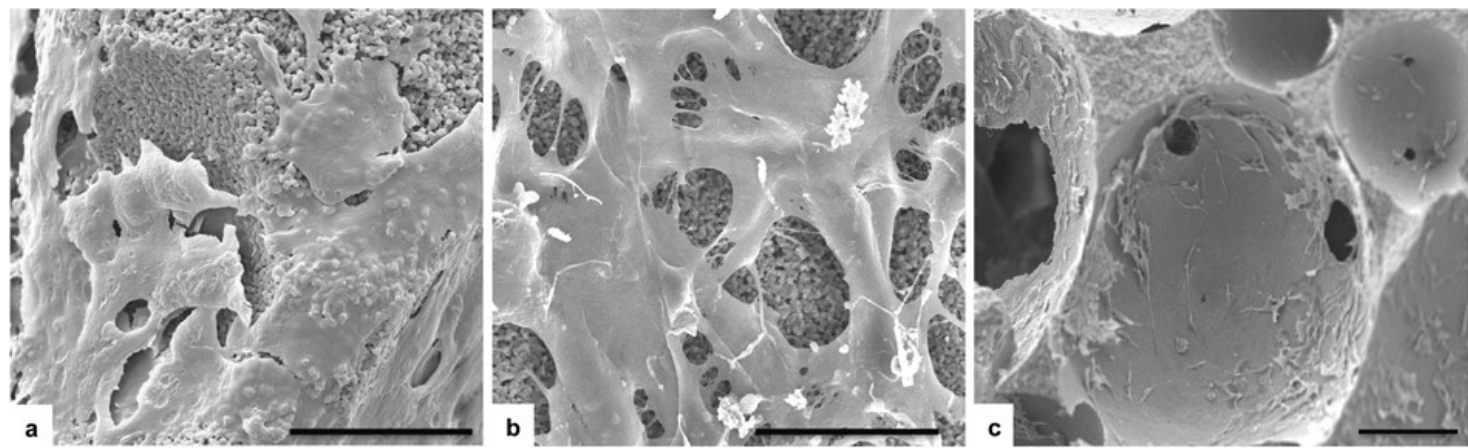

Figure 7. SEM analysis:upper scaffold surface of group HA and sample B respectively (A-B). After 7 days the cells covered almost all the surface showing a well spread morphology. Due to the interconnected porosity, cells grew also in the inner surface of the scaffolds. Here, the detail refers to the sample C. (Scale bars $40 \mu \mathrm{m}$ ).

porosity. Magnetite component seemed to do not negatively influence cell behaviour. Further investigations are ongoing in order to assess cell behaviour in a long term culture in presence of a magnetic field.

\section{Conclusions}

The present work highlighted that porous magnetic bone scaffolds could be prepared by foaming process within a wide range of compositions, satisfying several requirements for application in bone tissue engineering, that is: wide open and interconnected submicro-ultramacro pores, good mechanical strength as well as cytocompatibility, cell viability and osteoconductivity, as assessed by qualitative and quantitative analysis. Besides, magnetic properties enabling hyperthermia-based therapies could be maintained in the final scaffold, thanks to the presence of the apatitic matrix that aided to preserve the crystal habitus of magnetite nanoparticles therein embedded, against decomposition into less functional iron oxides such as hematite, during the thermal consolidation treatment. Furthermore, the presence of magnetite did not sort negative effects on the biological performances of the scaffolds, even at the highest concentration of iron oxide (up to $50 \%$ ). Therefore, the use of foaming processes to incorporate magnetite nanoparticles into apatitic matrixes is a feasible and promising approach to produce superparamagnetic, bioactive bone scaffolds with ability of remote activation, thus possibly opening to smart, personalized therapies in nanomedicine and bone regeneration.

\section{References}

1. Calori GM, Mazza E, Colombo M, Ripamonti C (2011) The use of bone-graft substitutes in large bone defects: any specific needs? Injury 42 Suppl 2: S56-63. [Crossref]

2. Khan WS, Rayan F, Dhinsa BS, Marsh D (2012) An Osteoconductive, Osteoinductive, and Osteogenic Tissue-Engineered Product for Trauma and Orthopaedic Surgery: How Far Are We? Stem Cells International 236231.

3. Panseri S, Russo A, Cunha C, Bondi A, Di Martino A, Patella S, Kon E (2011) Osteochondral tissue engineering approaches for articular cartilage and subchondral bone regeneration. Knee Surg Sports Traumatol Arthrosc 20: 1182-1191.

4. Sprio S, Ruffini A, Valentini F, D'Alessandro T, Sandri M, Panseri S, Tampieri A (2011) Biomimesis and biomorphic transformations: new concepts applied to bone regeneration. J Biotechnol 156: 347-355.

5. Shin H, Jo S, Mikos AG (2003) Biomimetic materials for tissue engineering. Biomaterials 24: 4353- 4364.

6. Boyan BD, Hummert TW, Dean DD, Schwartz Z (1996) Role of material surfaces in regulating bone and cartilage cell response. Biomaterials 17: 137-146. [Crossref]

7. Wang H, Li Y, Zuo Y, Li J, Ma S, Cheng L (2007) Biocompatibility and osteogenesis of biomimetic nano-hydroxyapatite/polyamide composite scaffolds for bone tissue engineering. Biomaterials 28: 3338-3348.

8. Zhang Y, Zhang M (2002) Three-dimensional macroporous calcium phosphate bioceramics with nested chitosan sponges for loadbearing bone implants. $J$ Biomed
Mater Res 61: 1-8.

9. Tampieri A, Celotti G, Sprio S, Delcogliano A, Franzese S (2001) Porosity-graded hydroxyapatite ceramics to replace natural bone. Biomaterials 22: 1365-1370. [Crossref]

10. Cunha C, Sprio S, Panseri S, Dapporto M, Marcacci M, Tampieri A. (2013) High biocompatibility and improved osteogenic potential of novel Ca-P/titania composite scaffolds designed for regeneration of loadbearing segmental bone defects. $J$ Biomed Mater Res: Part A. 101A: 1612-1619.

11. Dunn JC, Chan WY, Cristini V, Kim JS, Lowengrub J, et al. (2006) Analysis of cell growth in three-dimensional scaffolds. Tissue Eng 12: 705-716. [Crossref]

12. Freed LE, Marquis JC, Langer R, Vunjak-Novakovic G (1994) Kinetics of chondrocyte growth in cell-polymer implants. Biotechnol Bioeng 43: 597-604. [Crossref]

13. Kuboki Y, Jin Q, Kikuchi M, Mamood J, Takita H (2002) Geometry of artificial ECM: sizes of pores controlling phenotype expression in BMP-induced osteogenesis and chondrogenesis. Connect Tissue Res 43: 529-534.

14. Khaled EG, Saleh M, Hindocha S, Griffin M, Khan WS (2011) Tissue engineering for bone production- stem cells, gene therapy and scaffolds. Open Orthop $J 5$ Suppl 2: 289-295. [Crossref]

15. Bernhardt A, Lode A, Peters F, Gelinsky M (2011) Novel ceramic bone replacement material Osbone ${ }^{\circledR}$ in a comparative in vitro study with osteoblasts. Clin Oral Implants Res 22: 651-657. [Crossref]

16. Puppi D, Chiellini F, Piras AM, Chiellini E (2010) Polymeric materials for bone and cartilage repair, Progr Polym Sci 35: 403-440.

17. Chen RR, Mooney DJ (2003) Polymeric growth factor delivery strategies for tissue engineering. Pharm Res 20: 1103-1112. [Crossref]

18. Panseri S, Cunha C, D’Alessandro T, Sandri M, Russo A, Giavaresi G, Marcacci M Hung CT, Tampieri A (2012) Magnetic Hydroxyapatite Bone Substitutes to Enhance Tissue Regeneration: Evaluation In Vitro Using Osteoblast-Like Cells and In Vivo in a Bone Defect. PLoS ONE 7: e38710.

19. Valmikinathan CM, Wang J, Smiriglio S, Golwala NG, Yu X (2009) Magnetically induced protein gradients on electrospun nanofibers. Comb Chem High Throughput Screen 12: 656-663. [Crossref]

20. Foy SP, Manthe RL, Foy ST, Dimitrijevic S, Krishnamurthy N, et al. (2010) Optica imaging and magnetic field targeting of magnetic nanoparticles in tumors. ACS Nano 4: 5217-5224. [Crossref]

21. Hua MY, Yang HW, Chuang CK, Tsai RY, Chen WJ, et al. (2010) Magnetic nanoparticle- modified paclitaxel for targeted therapy for prostate cancer. Biomaterials 31: 7355-7363.

22. Phillips MA, Gran ML, Peppas NA (2010) Targeted Nanodelivery of Drugs and Diagnostics. Nano Today 5: 143-159. [Crossref]

23. Polyak B, Fishbein I, Chorny M, Alferiev I, Williams D, et al. (2008) High Field Gradient Targeting of Magnetic Nanoparticle-Loaded Endothelial Cells to the Surfaces of Steel Stents. Proc Natl Acad Sci USA 105: 698-703.

24. Amirfazli A (2007) Nanomedicine: magnetic nanoparticles hit the target. Nat Nanotechnol 2: 467-468.

25. Arruebo M, Fernandez Pacheco R, Ibarra MR, Santamaria J (2007) Magnetic Nanoparticles for Drug Delivery. Nano Today 2: 22-32. 
26. Kanczler JM, Sura HS, Magnay J, Green D, Oreffo RO, Dobson JP, E1 Haj AJ (2010) Controlled differentiation of human bone marrow stromal cells using magnetic nanoparticle technology. Tissue Eng Part A 16: 3241-3250.

27. Tampieri A, Sprio S, Sandri M, Valentini F (2011) Mimicking natural biomineralization processes: a new tool for osteo-chondral scaffold development Trends in Biotech 29: 526-535.
28. Gonzenbach UT, Studart AR, Tervoort E, Gauckler LJ (2006) Stabilization of foams with inorganic colloidal particles. Langmuir 22: 10983-10988. [Crossref]

29. Keaveny TM. Cancellous bone. In: Black J, Hastings G, editors. Handbook of biomaterial properties. London: Chapman \& Hall 15-23.

30. Tampieri A, Celotti G, Sprio S, Delcogliano A, Franzese S (2001) Porosity-graded hydroxyapatite ceramics to replace natural bone. Biomaterials 22: 1365-1370. [Crossref]

Copyright: (C2017 Tampieri A. This is an open-access article distributed under the terms of the Creative Commons Attribution License, which permits unrestricted use, distribution, and reproduction in any medium, provided the original author and source are credited. 